\title{
Body composition and energy expenditure in a population of children and adolescents with myelomeningocele
}

\author{
Carolina Caminiti, M.D. ${ }^{a}$, Carola Saure, M.D. ${ }^{a}$, Julieta Weglinski, M.D. ${ }^{a}$, \\ Fernanda de Castro, M.D. ${ }^{b}$ and Liliana Campmany, M.D. ${ }^{c}$
}

\begin{abstract}
Introduction. Myelomeningocele is a congenital defect that occurs when the neural tube fails to close completely. It causes body composition alterations and a high prevalence of obesity. It is difficult to detect the most adequate indicator for a nutritional diagnosis due to the impossibility of recording accurate anthropometric measurements.

Objective. To describe body composition, resting energy expenditure and metabolic disorders in a population of patients with myelomeningocele managed at "Hospital Garrahan" by comparing obese patients with myelomeningocele and a control population with multifactorial obesity. Population and methods. An anthropometry, an impedance analysis, skinfold equations, arm circumference equations, indirect calorimetry, and biochemical determinations were done to all patients with myelomeningocele between June 2013 and April 2014, once the informed consent had been signed.

Results. 131 patients aged 0.7-18.6 years were assessed; they were classified according to their body mass index Z-score into low weight (15\%), normal weight $(42 \%)$, overweight $(12 \%)$, and obese (31\%). A high correlation (r: 20.74) was observed between the fat mass $\%$ measured by impedance analysis versus that estimated using skinfolds. Patients with a high fat mass $\%$ had a higher body mass index Z-score than those with a normal fat mass \% (1.07 versus -0.27 , p: 0.0001) although both values were within normal parameters. A lower resting energy expenditure was observed among obese patients with myelomeningocele than predicted and in comparison with multifactorial obese controls. Conclusions. A high percentage of overweight/ obesity was found in the population with myelomeningocele. Skinfold equations would be more adequate to detect obesity. Obese patients with myelomeningocele had a lower resting energy expenditure than predicted and in comparison with controls. Energy indication should be customized.

Key words: myelomeningocele, obesity, energy expenditure, body composition.
\end{abstract}

http:/ / dx.doi.org/10.5546/ aap.2018.eng.e8

To cite: Caminiti C, Saure C, Weglinski J, et al. Body composition and energy expenditure in a population of children and adolescents with myelomeningocele. Arch Argent Pediatr 2018;116(1):e8-e13.

\section{INTRODUCTION}

Myelomeningocele is a congenital defect resulting from the defective closure of the neural tube during the fourth week of gestation. It is associated with sensory and motor impairments that vary depending on size and location. ${ }^{1}$ The incidence of myelomeningocele is approximately 1-2 cases every 1000 live births but differs widely from one country to the other. ${ }^{2-4}$

An abnormal intrauterine position causes significant congenital orthopedic diseases that worsen during early childhood due to muscle imbalance, postural effects, growth, etc. Eighty percent of children with upper lumbar injuries have short stature; the causes include lower limb hypoplasia, scoliosis, ${ }^{1}$ recurrent urinary tract infections, chronic renal failure, etc.

Children with myelomeningocele are at risk for different nutritional disorders. In average, obesity prevalence among patients with myelomeningocele is $42 \%$ due to an increased fat mass (FM) combined with an important lean mass (LM) deficit. Obesity may lead to worsening of comorbidities, such as restricted ability to move about, pressure ulcers, and a lower level of autonomy, compromising the quality of life, ${ }^{6}$ and metabolic consequences, such as insulin resistance (IR), carbohydrate intolerance, diabetes mellitus, fatty liver, dyslipidemia, arterial hypertension (HTN), obstructive sleep apnea syndrome, and increased cardiovascular risk, among others. ${ }^{7,8}$

Because of the orthopedic pathology described above, it is difficult to make accurate measures 
and use traditional indicators, such as body mass index (BMI), and together with the alteration in body composition, it becomes difficult to make an anthropometric diagnosis. ${ }^{9}$ Several studies have analyzed the use of more adequate cut-off points and different measures ${ }^{5}$ with varying results. One of the nutritional challenges seen in patients with myelomeningocele is detecting the most adequate indicator to diagnose obesity. ${ }^{4}$ Some of the consequences of an incorrect anthropometric diagnosis are over-estimating energy requirements and under-estimating the presence of metabolic complications.

\section{OBJECTIVE}

To describe, in a population of patients with myelomeningocele managed at Hospital Nacional de Pediatría "Prof. Dr. Juan P. Garrahan," body composition, resting energy expenditure (REE), and metabolic disorders, and to compare patients with myelomeningocele and obesity to a control population with multifactorial obesity.

\section{POPULATION AND METHODS}

This was an analytical, prospective, and observational study. All male and female children and adolescents with myelomeningocele managed at Hospital de Pediatría "Prof. Dr. Juan P. Garrahan" between June 2013 and April 2014 who agreed to participate in the study and who signed the informed consent were included in the study by consecutive sampling. The study was approved by the hospital's Ethics Committee. Weight was measured using an electronic platform scale for gurneys; height was measured using a wall altimeter for those who could walk whereas an infantometer in the dorsal recumbent position was used for those who could not. The weight/age and height/age percentile tables were estimated using the World Health Organization's (WHO) standards for subjects younger than 60 months old, and Argentine tables were used for subjects as of 61 months old. ${ }^{10} \mathrm{BMI}$ was estimated as weight/ height ${ }^{2}$; BMI percentiles were calculated using the WHO's standards and patients were classified into low weight for a BMI $<$ P5, normal weight for a BMI P5-84, overweight for a BMI $\geq$ P85- $<95$, and obese for a BMI $\geq$ P95.

Blood pressure (BP) was recorded using a cuff that covered two-thirds of the upper arm (sphygmomanometer), with the patient in sitting position and after resting for 10 minutes. BP percentiles were estimated using the Task Force references. ${ }^{11}$ HTN was assumed in the case of a systolic and/or diastolic BP $\geq$ P95. Patients with HTN were referred to a specialist for confirmation and the corresponding tests. Tricipital, subscapular, and suprailiac skinfolds were measured using a skinfold caliper graduated in $\mathrm{mm}$, and arm circumference was measured using a non-extensible tape measure at the mid-point between the olecranon process and the acromium. In both cases, percentiles were estimated up to 60 months old based on the WHO's standards, and using the Argentine references as of 61 months old. ${ }^{10}$

Tanner staging was used to classify patients into prepubertal and pubertal.

The blood glucose level was determined by glucose-oxidase; insulin, by radioimmunoassay using a commercial kit; total cholesterol and triglycerides, using the CHOD-PAP-enzymatic colorimetric method; HDL cholesterol and LDL cholesterol, using the CHOD-PAP method with heparin precipitation. Dyslipidemia was defined as HDL $<40 \mathrm{mg} / \mathrm{dL}$ and/or triglycerides $>110 \mathrm{mg} / \mathrm{dL} .{ }^{12}$ All determinations were done following a 12 hour fasting.

IR was estimated using the homeostatic model assessment (HOMA $)^{13}$ using the baseline insulin $(\mu \mathrm{U} / \mathrm{L}) \times$ baseline glucose $(\mathrm{mg} / \mathrm{dL} / 18) / 22.5$ formula. IR was defined as a value $\geq 2.5$ ( $>2$ standard deviations [SD] of the mean in a control population). ${ }^{14}$

Patients were classified into three groups based on their baseline blood glucose level: normal $(<110 \mathrm{mg} / \mathrm{dL})$, altered fasting blood glucose level (110-126 mg/dL), and diabetic (>126 mg/dL).

Body composition was estimated by monofrequency bioelectrical impedance analysis. In addition, fat mass percentage (FM\%) was estimated based on skinfold thickness using the following equations:

1. ${ }^{(15)}$ Girls: $1.21 \times$ (tricipital + subscapular skinfold) $-0.008 \times$ (tricipital + subscapular skinfold $)^{2}-1.7$.

2. ${ }^{(15)}$ Boys: $1.33 \times$ (tricipital + subscapular skinfold $)-0.013 \times$ (tricipital + subscapular skinfold $)^{2}-2.5$.

LM was estimated as arm circumference $(\mathrm{cm}) /$ [3.14 $\times$ tricipital skinfold $(\mathrm{mm})]$.

FM\% was considered high if it was $\geq \mathrm{P} 90$ of the references by McCarthy et al. ${ }^{16}$

REE was estimated with an indirect calorimetry using gas exchange with measurement of oxygen $\left(\mathrm{O}_{2}\right)$ uptake and carbon dioxide $\left(\mathrm{CO}_{2}\right)$ production (CCM Express by 
Medgraphics) during 20 minutes after resting for 20 minutes.

Patients with myelomeningocele and obesity were compared to a population of multifactorial obese subjects managed by the Department of Nutrition who had no other disease and who were not receiving any drug. Both populations were paired by age and sex before comparing them.

A descriptive and analytical assessment was done. First of all, each outcome measure behavior was described and, based on their distribution, mean and its corresponding SD were reported for outcome measures with a normal distribution, and median and range, for those with a biased distribution. Student's $t$ test and the Wilcoxon rank-sum test were used for normal and biased distribution outcome measures, respectively. Categorical outcome measures were analyzed using the $\chi^{2}$ /Fisher test. A linear regression was done to establish the size of correlation among determined outcome measures. A two-tailed test and a statistical significance of $p<0.05$ were assumed.

\section{RESULTS}

A total of 131 patients diagnosed with myelomeningocele were assessed. All patients

TABLE 1. Demographic and clinical outcome measures of patients with myelomeningocele

\begin{tabular}{lc}
\hline Outcome measures & Patients with myelomeningocele \\
& $\mathbf{N = 1 3 1}$ \\
\hline Age (years) & $8.1(0.7 / 18.6)$ \\
Weight (kg) & $22(6.3 / 79)$ \\
Weight Z-score & $-0.2(-4.4 / 4)$ \\
Height (cm) & $116 \pm 29.3$ \\
Height Z-score & $-1.63(-7.5 / 3.9)$ \\
BMI (kg/height $\left.{ }^{2}\right)$ & $19 \pm 4.8$ \\
BMI Z-score & $0.88(-5.3 / 4.4)$ \\
Waist (cm) & $65.2 \pm 12$ \\
Arm circumference (cm) & $20.5 \pm 5.7$ \\
Bicipital skinfold (mm) & $8.4 \pm 3.3$ \\
Tricipital skinfold (mm) & $10.5 \pm 3.9$ \\
Subscapular skinfold (mm) & $12.1 \pm 7$ \\
Suprailiac skinfold (mm) & $11.5 \pm 5.5$ \\
Systolic BP (mmHg) & $99 \pm 11.8$ \\
Diastolic BP (mmHg) & $60 \pm 12$ \\
\hline
\end{tabular}

BMI: body mass index; BP: blood pressure.

Mean or median values and their corresponding standard deviation and/or range are indicated according to the outcome measure distribution. agreed to participate. Their mean age was 8.1 years $(0.7-18.6)$, and $50 \%(65 / 131)$ were boys. Also, 58\% (44/131) were prepubertal children, and $33 \%(25 / 131)$ could walk. Table 1 shows the demographic and clinical outcome measures.

The population was categorized based on their BMI into low weight: $15 \%$ (19/131); normal weight: $42 \%$ (55/131); overweight: $12 \%$ (16/131); and obese: $31 \%(41 / 131)$.

A pathological waist circumference was observed in $25 \%$ (6/25 patients could walk). HTN was detected in $25 \%$ of patients $(19 / 131)$ with a single measurement. No patient had diabetes mellitus. An abnormal baseline blood glucose level was observed but then ruled out with a repeat measurement, which established that all studied patients had a normal fasting blood glucose level. IR was detected in 14\% (18) of patients. In relation to dyslipidemia, 13\% (17) had hypertriglyceridemia and 30\% (39), low HDL cholesterol levels. Table 2 shows the biochemical outcome measures.

An association was observed between acanthosis nigricans and IR (p: 0.04) but not with HTN or dyslipidemia.

A high FM $\%$ was detected in $66 \%$ of patients by means of an impedance analysis. No differences were observed in the $\mathrm{FM} \%$ or the lean mass percentage (LM\%) between patients who could walk and those who could not (FM\% $23.8 \pm 12.3$ versus $25.7 \pm 9.8$, p: 0.46 , and $\mathrm{LM} \%$ $76 \pm 1.5$ versus $74 \pm 1.7$, p: 0.37 , respectively). Likewise, no association was observed between FM $\%$ and waist circumference. Table 3 describes the body composition and energy expenditure outcome measures.

TABLE 2. Biochemical outcome measures of patients with myelomeningocele

\begin{tabular}{lc} 
Outcome measures & Patients with myelomeningocele \\
& $\mathbf{N = 1 3 1}$ \\
\hline Blood glucose level $(\mathrm{mg} / \mathrm{dL})$ & $84 \pm 11.4$ \\
Insulin $(\mu \mathrm{U} / \mathrm{mL})$ & $6.1(1 / 64.1)$ \\
HOMA & $1.28(0.12 / 6)$ \\
Total-c $(\mathrm{mg} / \mathrm{dL})$ & $147(80 / 252)$ \\
HDL-c $(\mathrm{mg} / \mathrm{dL})$ & $45.6(13 / 100.4)$ \\
LDL-c $(\mathrm{mg} / \mathrm{dL})$ & $95(38 / 203)$ \\
Triglycerides $(\mathrm{mg} / \mathrm{dL})$ & $66(34 / 286)$ \\
\hline
\end{tabular}

HOMA: homeostasis model assessment; c: cholesterol. Mean or median values and their corresponding standard deviation or range are indicated according to the outcome measure distribution. 
A high correlation $\left(\mathrm{r}^{2}: 0.74\right)$ was found between FM\% measured by impedance analysis and skinfold equations ( $23 \pm 12.2$ versus $20.5 \pm 8.9$, respectively). Also, a high correlation $\left(\mathrm{r}^{2}: 0.81\right)$ was found between absolute LM measured by impedance analysis and that measured by arm circumference and skinfolds $(20.1 \pm 11.5$ versus $17.2 \pm 4.9$, respectively).

Patients with a high FM\% had a significantly higher BMI Z-score than those with a normal FM\% (BMI Z-score: 1.07 versus -1.27, p: 0.00001), although both values were within normal parameters.

Among the patients who met the criterion for IR, only $54.5 \%$ were diagnosed with obesity based on their BMI Z-score, whereas $80 \%$ were diagnosed based on a high FM\%.

The REE measured in the entire studied myelomeningocele population was $881 \pm 283 \mathrm{cal}$, which was lower than predicted by the formula (REE: $77 \pm 21 \%$ of the predicted value).

Lastly, obese patients with myelomeningocele $(\mathrm{N}=31)$ were compared to multifactorial obese controls $(\mathrm{N}=27)$, paired by age and sex. The median age of both populations was $9.2 \pm 2.8$ versus $10 \pm 1.69$ years, p: 0.23 , respectively (age range: $4.4-14.7$ years). Comparative data are shown in Table 4.

The population of obese patients with myelomeningocele showed a significantly lower rate of obesity than controls (BMI Z-score: $2.2 \pm 1.6$ versus $3.4 \pm 1.2$, p: 0.0001 ), although no significant differences were observed in terms of FM $\%$ (30 \pm 7.7 versus $33 \pm 5.6 \%$, p: 0.14 ).

In addition, although FM was the same, myelomeningocele patients had a lower REE than controls ( $82 \pm 23$ versus $108 \pm 23.9 \%$, p: 0.0048).

TABLE 3. Body composition and energy expenditure outcome measures of patients with myelomeningocele

\begin{tabular}{lc}
\hline Outcome measures & Patients with myelomeningocele \\
& $\mathbf{N = 1 3 1}$ \\
\hline Lean mass $(\mathrm{kg})$ & $20 \pm 11.5$ \\
Lean mass $(\%)$ & $75.5(47 / 97)$ \\
Fat mass $(\mathrm{kg})$ & $7.2 \pm 6.9$ \\
Fat mass $(\%)$ & $24.6(2.7 / 53)$ \\
REE (cal/day) & $881 \pm 283$ \\
$\%$ of predicted value & $80 \pm 21.3$ \\
\hline
\end{tabular}

REE: resting energy expenditure measured by indirect calorimetry; \% of predicted value: measured energy expenditure versus that estimated by a formula. Mean or median values and their corresponding standard deviation or range are indicated according to the outcome measure distribution.

\section{DISCUSSION}

Among patients with myelomeningocele, $43 \%$ were overweight/obese, which is consistent with what other authors, such as Fiore et al. ${ }^{17}$ and Littlewood et al., ${ }^{6}$ have reported. This percentage is higher than the average $31 \%$ prevalence observed in different Argentine age groups according to the National Survey on Nutrition and Health (Encuesta Nacional de Nutrición and Salud, ENNyS), ${ }^{18}$ but similar to what has been found by other national studies carried out in male and female adolescents. ${ }^{19}$

Among patients who could walk, 25\% had a pathological waist circumference but it was not associated with a high FM\%. Consistently with such lack of association, recent studies have demonstrated a greater lower limb FM in this population of patients..$^{20}$ It is also possible that the reduced number of patients in this category could have resulted in an underestimation of the relationship between both indicators.

HTN was detected in $25 \%$ of patients with a single measurement. However, although the causes of BP overestimation have already been described ${ }^{21}$ it is worth noting that the percentage was high compared to the publication about metabolic syndrome at a national level made by Mazza et al., ${ }^{19}$ who found a $13.5 \%$ HTN prevalence among obese adolescents. Organic causes that could account for such clinical finding should be ruled out, e.g., renal impairment.

In addition, although the percentage of obesity was higher than in the general population, a lower IR and dyslipidemia prevalence was observed, which is consistent with recent studies in myelomeningocele, ${ }^{22}$ but in dispute with the above mentioned studies in obese

TABLE 4. Body composition and energy expenditure outcome measures of obese patients with myelomeningocele versus multifactorial obese controls

\begin{tabular}{lccc}
\hline $\begin{array}{l}\text { Outcome } \\
\text { measure }\end{array}$ & $\begin{array}{c}\text { Obese patients } \\
\text { with myelomeningocele } \\
\mathbf{N = 3 1}\end{array}$ & $\begin{array}{c}\text { Multifactorial } \\
\text { obese controls }\end{array}$ & \\
\hline Age & $9.2 \pm 2.8$ & $10 \pm 1.69$ & 0.23 \\
BMI Z-score & $1.97 \pm 1.2$ & $3.4 \pm 1.2$ & 0.0001 \\
Lean mass (\%) & $69.4 \pm 7.7$ & $66 \pm 5.6$ & 0.14 \\
Fat mass (\%) & $30 \pm 7.7$ & $33 \pm 5.6$ & 0.14 \\
$\%$ of predicted REE & $82 \pm 23$ & $108 \pm 23.9$ & 0.0048 \\
\hline
\end{tabular}

BMI: body mass index; \% of predicted REE: energy expenditure as measured versus as predicted by a formula.

Mean or median values and their corresponding standard deviation or range are indicated according to the outcome measure distribution. 
adolescents. ${ }^{19}$ Lorenzana et al. ${ }^{20}$ confirmed an increase in intramuscular fat in the lower limbs, which, although it is a risk factor for metabolic complications compared to subcutaneous fat deposits, may justify an increase in peripheral versus central FM\%. Other studies ${ }^{23}$ also confirmed peripheral FM localization, particularly in the lower limbs.

If the $\mathrm{FM} \%$ is used, the percentage of obese patients with myelomeningocele increases to $66 \%$ compared to the BMI Z-score. However, as observed here, median BMI Z-scores are within normal, which confirms the underestimation of the size of obesity by BMI Z-score, in agreement with the publication by Liusuwan et al., ${ }^{9}$ who found no correlation between BMI and FM\%. Other studies, as the one by Nelson et al., ${ }^{24}$ found $74 \%$ of obese patients based on direct FM indicators versus $53 \%$ based on the BMI Z-score.

In this study, a high correlation was observed between FM\% by impedance analysis and skinfold equations, which is consistent with other studies that have found a high correlation between skinfold equations and the total body potassium method. ${ }^{8}$ In turn, a correlation was established between absolute LM by impedance analysis and arm circumference and skinfold equations, so both measurements would be adequate to assess body composition alterations in these patients. Grogan et al. ${ }^{25}$ found $50 \%$ less LM in children with myelomeningocele compared to controls.

Although in our study no significant difference was observed in body composition between children who could walk and those who could not, it is very important to detect LM based on studies such as the one by Buffart et al. ${ }^{26}$ on cardiovascular risk in adolescents and young adults with myelomeningocele, which found that patients who could walk had a higher level of physical activity, a lower FM\%, and a lower cardiovascular risk compared to those who could not. This highlights the importance of doing activities to improve body composition and increase LM.

The comparison of body composition between obese patients with myelomeningocele and multifactorial obese subjects paired by age and sex found that the former had a lower BMI $\mathrm{Z}$-score but a higher FM\%. This is consistent with recent studies, such as the one by Mueske et al. ${ }^{23}$

Finally, this study found a lower REE compared to predicted energy expenditure and to that of controls, in spite of the fact that both populations had a similar FM\%. Polfuss et al.8 recently published a literature review to date regarding energy expenditure in myelomeningocele patients. The three studies analyzing energy expenditure agreed that it was lower than predicted. The first study, conducted by L. Bandini et al. ${ }^{27}$ in 1991 in 16 adolescents with myelomeningocele found a lower REE than predicted and a lower total energy expenditure (TEE) among patients who could not walk. More recently, Littlewood et al. ${ }^{6}$ and Liusuwan et al. ${ }^{9}$ analyzed REE and TEE. The first study was carried out in 19 children with myelomeningocele and found that REE was highly variable $(96 \pm 18 \%$ of predicted value), whereas TEE was frankly reduced $(73.3 \%$ of predicted value). The second study assessed 66 patients with spina bifida aged 11-21 years and found a reduced REE in association with a lower LM. Based on the evidence, the bibliography agrees that the focus should be placed on reducing energy intake below the recommendations for healthy children to prevent obesity and its metabolic and nonmetabolic complications, as here above described.

This study has the following limitations: 1) lack of a gold standard method to estimate body composition (total body potassium); and 2) a reduced number of patients due to their categorization into subgroups, which may have underestimated the association among the different outcome measures. And the strengths of this study are as follows: 1) above all, the number of patients assessed by indirect calorimetry; and 2) its prospective nature.

\section{CONCLUSIONS}

A high obesity prevalence was observed in the myelomeningocele population managed in our hospital. Indicators based on skinfold thickness and arm circumference showed a statistically significant association with FM\% and absolute LM. Obese patients with myelomeningocele had a lower REE compared to predicted REE and the population of multifactorial obese patients.

\section{REFERENCES}

1. Sandler AD. Children with Spina Bifida: Key Clinical Issues. Pediatr Clin N Am 5010:57(4):879-92.

2. Buffart LM, Roebroeck ME, Rol M, et al. Triad physical activity, aerobic fitness and obesity in adolescents and young adults with myelomeningocele. J Rehabil Med 2008;40(1):70-5.

3. MayerS,WeisserM,TillH,etal.Congenitalmyelomeningocele - do we have to change our management? Cerebrospinal Fluid Res 2010;7:17.

4. Ponte SF, Rondon A, Bacelar H, et al. Anthropometric 
measurements as an indicator of nutritional status in spina bifida patients undergoing enterocystoplasty. Einstein (Sao Paulo) 2013;11(2):168-73.

5. Shurtleff D, Walker W, Duguay S, et al. Obesity and myelomeningocele: Anthropometric Measures. J Spinal Cord Med 2010;33(4):410-9.

6. Littlewood RA, Trocki O, Shepherd RW, et al. Resting energy expenditure and body composition in children with myelomeningocele. Pediatr Rehabil 2003;6(1):31-7.

7. Klein S, Burke LE, Bray GA, et al. Clinical implications of obesity with specific focus on cardiovascular disease, a statement for professionals from the American Heart Association Council of Nutrition, Physical Activity, and Metabolism endorsed by the American College of Cardiology Foundation. Circulation 2004;110(18):2952-67.

8. Polfuss M, Bandini LG, Sawin K. Obesity prevention for individuals with Spina Bifida. Curr Obes Res 2017;6(2): 116-26.

9. Liusuwan RA, Widman L, Abresch RT, et al. Body composition and resting energy expenditure in patients aged 11 to 21 years with spinal cord dysfunction compared to controls: comparisons and relationships among the groups. J Spinal Cord Med 2007;30(Suppl 1):S105-11.

10. Comité Nacional de Crecimiento y Desarrollo. Guías para la evaluación del crecimiento físico. Buenos Aires: Sociedad Argentina de Pediatría; 2013.

11. National High Blood Pressure Education Program Working Group on High Blood Pressure in Children and Adolescents. The Fourth Report on the Diagnosis, Evaluation and Treatment of High Blood Pressure in Children and Adolescents. Pediatrics 2004;114(2Suppl4th Report):555-76.

12. Cook S, Auinger P, Huang TT. Growth curves for cardiometabolic risk factors in children and adolescents. J Pediatr 2009;155(3):S6.e15-26.

13. Haffner S, Miettinen H, Stern M. The Homeostasis Model in the San Antonio Heart Study. Diabetes Care 1997;20(7): 1087-92.

14. Guntsche Z, Guntsche EM, Saravi FD, et al. Umbilical waist-to-height ratio and trunk fat index (DXA) as markers of central adiposity and insulin resistance in Argentinean children with a family history of metabolic syndrome. $J$ Pediatr Endocrinol Metab 2010;23(3):245-56.

15. Slaughter MH, Lohman TG, Boileau RA, et al Skinfold equations for estimation of body fatness in children and youth. Hum Biol 1988;60(5):709-23.
16. McCarthy HD, Cole TJ, Fry T, et al. Body fat reference curves for children. Int J Obes (Lond) 2006;30(4):598-602.

17. Fiore P, Picco P, Castagnola E, et al. Nutritional Survey of children and adolescents with myelomeningocele. Overweight associated with reduced energy intake. Eur J Pediatr Surg 1998;8(Suppl 1):34-6.

18. Argentina. Ministerio de Salud. Encuesta Nacional de Nutrición y Salud. Respuestas de la gente. Propuestas para el país. Documentos de resultados 2007. [Accessed on: August 9th, 2017]. Available at: http:/ / www.msal. gob.ar/images/ stories/ bes / graficos / 0000000257 cnt-a08ennys- documento-de-resultados-2007.pdf.

19. Mazza C, Evangelista P, Figueroa A, et al. Estudio clinico del síndrome metabólico en niños y adolescentes de Argentina. Rev Argent Salud Pública 2011;2(6):25-33.

20. Lorenzana D, Mueske N, Ryan D, et al. Quantitative analysis of lower leg adipose tissue distribution in youth with myelomeningocele. J Child Neurol 2016;31(8):979-81.

21. Grupo de Hipertensión. Consenso sobre factores de riesgo de enfermedad cardiovascular en pediatría. Hipertensión arterial en el niño y el adolescente. Arch Argent Pediatr 2005;103(4):348-66.

22. Liusuwan MS, Widman LM, Abresch RT, et al. Behavioral intervention, exercise and nutrition education to improve health and fitness (BENEfit) in adolescents with mobility imparement due to spinal cord dysfunction. Spinal Cord Med 2007;30(Suppl 1):S119-26.

23. Mueske NM, Ryan DD, Van Speybroeck AL, et al. Fat distribution in children and adolescents with myelomeningocele. Dev Med Chid Neurol 2015;57(3):273-8.

24. Nelson M, Widman LM, Abresch RT, et al. Metabolic Syndrome in Adolescents With Spinal Cord Dysfunction. J Spinal Cord Med 2007;30(Suppl 1):S127-39.

25. Grogan C, Ekwall SM. Body composition of children with myelomeningocele, determined by $\mathrm{K} 40$, urinary creatinine and anthropometric measures. J Am Col Nutr 1999;18(4):316-23.

26. Buffart LM, van der Berg-Emmons RJ, Burdorf A, et al. Cardiovascular disease risk factors and the relationship with physical activity, aerobic fitness, and body fat in adolescents and adults with myelomeningocele. Arch Phys Med Rehabil 2008;89(11):2167-73.

27. Bandini L, Schoeller D, Fukugawa N, etal.Body composition and energy expenditure in adolescents with cerebral palsy or myelodisplasia. Pediatr Res 1991;29(1):70-7. 